EUROPEAN ORGANIZATION FOR NUCLEAR RESEARCH

European Laboratory for Particle Physics

\title{
NEUTRON IRRADIATION TESTS OF PRESSURE TRANSDUCERS IN LIQUID HELIUM
}

\author{
J.F. Amand ${ }^{1}$, T. Bager ${ }^{1,}$ J. Casas-Cubillos ${ }^{1}$ and J.P. Thermeau ${ }^{2}$
}

\begin{abstract}
The superconducting magnets of the future Large Hadron Collider (LHC) at CERN will operate in pressurised superfluid helium (1 bar, $1.9 \mathrm{~K}$ ). About 500 pressure transducers will be placed in the liquid helium bath for monitoring the filling and the pressure transients after resistive transitions. Their precision must remain better than 100 mbar at pressures below 2 bar and better than 5\% for higher pressures (up to 20 bar), with temperatures ranging from $1.8 \mathrm{~K}$ to $300 \mathrm{~K}$. All the tested transducers are based on the same principle: the fluid or gas is separated from a sealed reference vacuum by an elastic membrane; its deformation indicates the pressure. The transducers will be exposed to high neutron fluence ( $2 \mathrm{kGy}, 1014$ $\mathrm{n} / \mathrm{cm} 2$ per year) during the 20 years of machine operation. This irradiation may induce changes both on the membranes characteristics (leakage, modification of elasticity) and on gauges which measure their deformations. To investigate these effects and select the transducer to be used in the LHC, a neutron irradiation program is being performed at the CERI cyclotron (CNRS Orléans, France): a cryostat is installed on a beam line, transducers are immersed in liquid helium and irradiated by neutrons (1-20 MeV, $1015 \mathrm{n} / \mathrm{cm} 2$ ). The tested transducers measure the helium bath pressure, the true value of which is given by a warm, unirradiated sensor. Every readout is acquired on-line. This paper presents the results of the first experiments performed during spring, 1999.
\end{abstract}

1 LHC Division, CERN, 1211 Geneva 23

2 Institut de Physique Nucléaire d'Orsay, CNRS/IN2P3, Orsay, 91406 Cedex, France

Presented at the 1999 Cryogenic Engineering and International Cryogenic Materials Conference (CEC-ICMC'99), 12-16 July 1999, Montreal, Canada

\footnotetext{
Administrative Secretariat

LHC Division

CERN

CH - 1211 Geneva 23

Switzerland

Geneva, 1 December 1999
} 


\title{
NEUTRON IRRADIATION TESTS OF PRESSURE TRANSDUCERS IN LIQUID HELIUM
}

\author{
J.F. Amand, ${ }^{1}$ T. Bager, ${ }^{1}$ J. Casas-Cubillos, ${ }^{1}$ and J.P. Thermeau ${ }^{2}$ \\ ${ }^{1}$ CERN-LHC Division \\ CH-1211, Geneva 23, Switzerland \\ ${ }^{2}$ Institut de Physique Nucléaire d'Orsay, CNRS/IN2P3 \\ Orsay, 91406 Cedex, France
}

\begin{abstract}
The superconducting magnets of the future Large Hadron Collider (LHC) at CERN will operate in pressurised superfluid helium (1 bar, $1.9 \mathrm{~K}$ ). About 500 pressure transducers will be placed in the liquid helium bath for monitoring the filling and the pressure transients after resistive transitions. Their precision must remain better than 100 mbar at pressures below 2 bar and better than $5 \%$ for higher pressures (up to 20 bar), with temperatures ranging from $1.8 \mathrm{~K}$ to $300 \mathrm{~K}$. All the tested transducers are based on the same principle: the fluid or gas is separated from a sealed reference vacuum by an elastic membrane; its deformation indicates the pressure. The transducers will be exposed to high neutron fluence $\left(2 \mathrm{kGy}, 10^{14} \mathrm{n} / \mathrm{cm}^{2}\right.$ per year) during the 20 years of machine operation. This irradiation may induce changes both on the membranes characteristics (leakage, modification of elasticity) and on gauges which measure their deformations. To investigate these effects and select the transducer to be used in the LHC, a neutron irradiation program is being performed at the CERI cyclotron (CNRS Orléans, France): a cryostat is installed on a beam line, transducers are immersed in liquid helium and irradiated by neutrons $\left(1-20 \mathrm{MeV}, 10^{15} \mathrm{n} / \mathrm{cm}^{2}\right)$. The tested transducers measure the helium bath pressure, the true value of which is given by a warm, unirradiated sensor. Every readout is acquired on-line. This paper presents the results of the first experiments performed during spring, 1999.
\end{abstract}

\section{INTRODUCTION}

For controlling the cryogenic parameters of the LHC magnets, the inner pressure of the helium loop is an important measurement. It allows the control of vessel filling, and can help in magnet quench propagation studies. About 500 pressure transducers are needed to monitor the 
pressure of cryogenic vessels around $27 \mathrm{~km}$ of LHC ring. The aim of this study is to investigate the possibility of immersing the transducers in the liquid helium of the cold masses. They must work in liquid helium and gas, at a temperature ranging from $1.8 \mathrm{~K}$ to $300 \mathrm{~K}$, and must keep their precision better than 100 mbar below 2 bar, and better than $5 \%$ for higher pressure (up to 20 bar). Two types of problems may be encountered with cold transducers. The first is their intrinsic behaviour in liquid helium at cryogenic temperature, because most of the transducers were not primarily designed to be used for such conditions; this is the object of another paper ${ }^{2}$. The second possible problem, which is the subject of this paper, is the effect of high neutron fluence: if placed in the cold mass, close to the quadrupoles, the transducers may receive about $10^{14} \mathrm{n} / \mathrm{cm}^{2}$ per year ( $2 \mathrm{kGy}$ neutrons) ${ }^{1}$. A neutron irradiation campaign is being performed to investigate the possible effects. To be as close as possible to the LHC conditions, the sensors are irradiated by neutrons at low temperature, immersed in liquid helium.

\section{TESTED TRANSDUCERS}

All the tested transducers are based on the same principle (Figure 1). The pressure is deduced from the flexion of an elastic membrane placed between the measured fluid and a reference vacuum. The displacement of the membrane is measured by resistive strain gauges placed on its surface on three different types. The transducer contains built-in passive electronic devices to supply the power to the strain gauges and deliver an analog signal. Several sensors, the signals of which are strongly temperature dependent, contain an integrated thermometer. The possible effects that may occur under irradiation are leakage of the reference vacuum, degradation of the strain gauges, modification of membranes elasticity and problems with built-in electronics or temperature sensors. Four types of commercial transducers have been tested in the irradiation facility (Table 1). However some modifications were necessary: the stainless steel bodies are incompatible with neutron irradiation because of the high activation of this material. The stainless steel of the tested samples has been replaced by lowactivation metal (aluminium or copper-beryllium alloy).

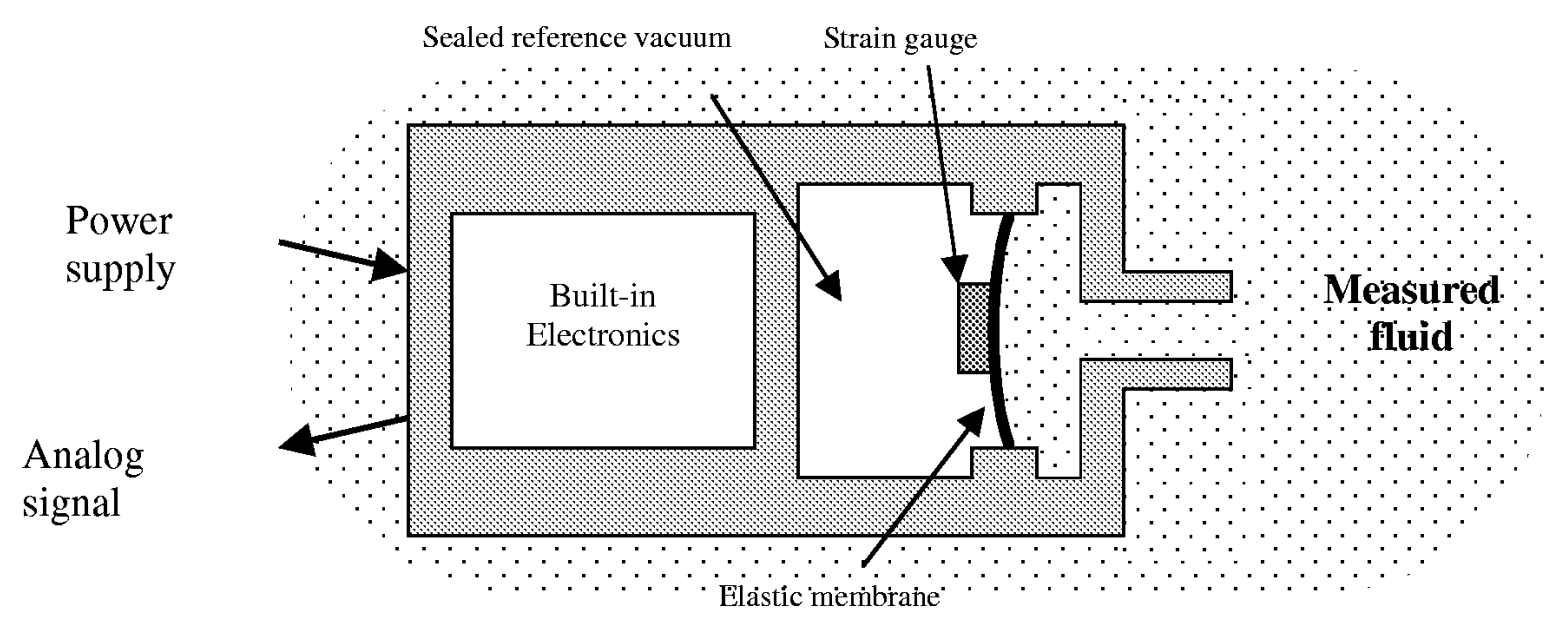

Figure 1. Scheme of a generic cold pressure transducer. On some sensors, the strain gauge may be replaced by an inductive sensing system. 
Table 1. List of tested pressure transducers

\begin{tabular}{ccccc}
\hline & Sensor 1 & Sensor 2 & Sensor 3 & Sensor 4 \\
\hline Membrane & Metal (W1.4542) & Metal (Inconel) & $\mathrm{SiO}_{2}$ & $\mathrm{SiO}_{2}$ \\
Body & $\mathrm{Al}$ & $\mathrm{Cu}-\mathrm{Be}$ alloy & $\mathrm{Al}$ & $\mathrm{Al}$ \\
$\begin{array}{c}\text { (modified) } \\
\text { Built-in }\end{array}$ & Pt resistor & - & $\mathrm{Si} \mathrm{diode}$ & - \\
$\begin{array}{c}\text { Thermometer } \\
\text { Dimensions } \\
\mathrm{D} \times 1 \text { (mm) }\end{array}$ & $20 \mathrm{~mm} \times 50 \mathrm{~mm}$ & $50 \mathrm{~mm} \times 15 \mathrm{~mm}$ & $20 \mathrm{~mm} \times 40 \mathrm{~mm}$ & $15 \mathrm{~mm} \times 40 \mathrm{~mm}$ \\
$\begin{array}{c}\text { Sensing principle } \\
\text { Number of tested } \\
\text { samples }\end{array}$ & $\begin{array}{c}\text { Metallic resistive } \\
\text { strain gauge }\end{array}$ & Inductive & $\begin{array}{c}\text { Piezoresistive } \\
\text { strain gauge }\end{array}$ & $\begin{array}{c}\text { Metallic resistive } \\
\text { strain gauge }\end{array}$ \\
\hline
\end{tabular}

\section{EXPERIMENTAL FACILITY}

The irradiation facility is composed of a cryostat (Figure 2) installed on a beam line of the CERI cyclotron (Orléans, France). This set-up reproduces partially the LHC conditions: the samples are irradiated at low temperature (immersed in liquid helium, from $1.7 \mathrm{~K}$ to $4.2 \mathrm{~K}$ ); the total neutron dose is equivalent to that expected in the machine. An on-line acquisition system takes the data during the whole experiment.

\section{Irradiation Aspect of the Facility}

The neutrons are generated by a deuteron beam (20 MeV, up to $35 \mu \mathrm{A}$ ) colliding a beryllium target. The ${ }^{9} \mathrm{Be}+\mathrm{d} \rightarrow{ }^{10} \mathrm{~B}+\mathrm{n}$ reaction produces neutrons with energy between 1 and $20 \mathrm{MeV}$ and low gamma dose $(20 \%)$. The total dose of $10^{15} \mathrm{n} / \mathrm{cm}^{2}$ (equivalent of 10 years of LHC operation at full intensity) can be attained in 20 hours of exposure. The dose is measured by small nickel foils (mass: $15 \mathrm{mg}$ ), the neutron activation of which gives the total fluence.

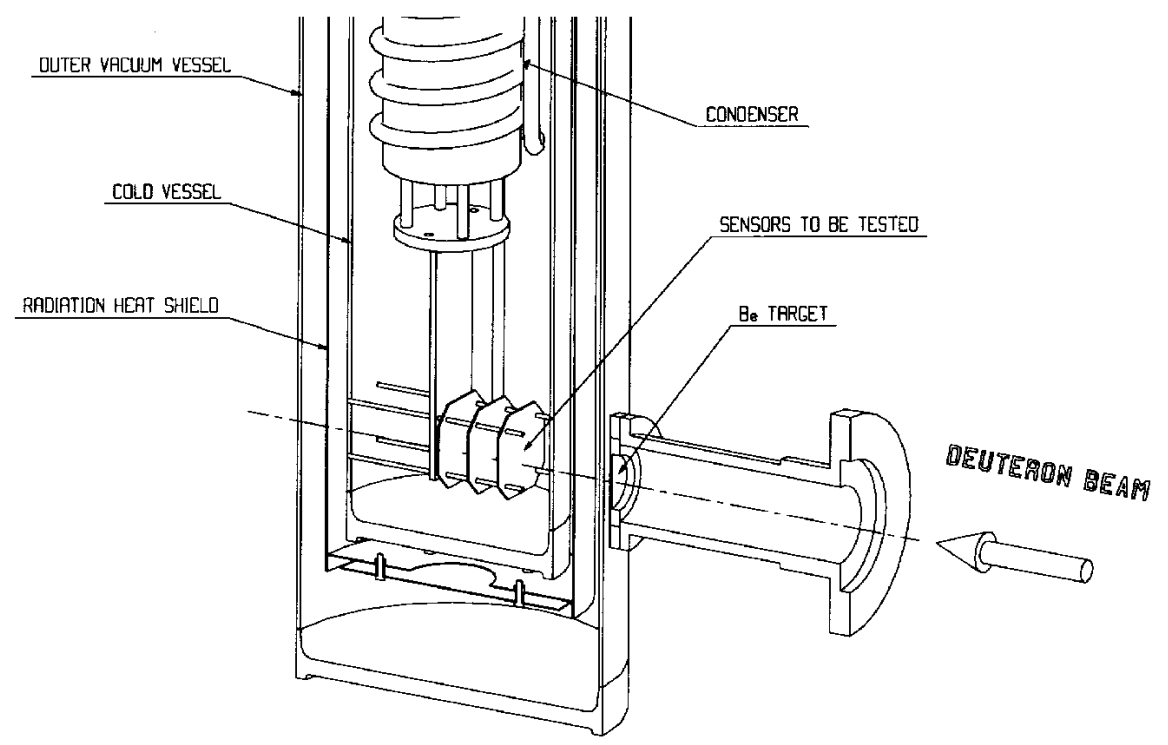

Figure 2. The irradiation cryostat. 


\section{Cryogenic Aspects}

The cryostat is made of a liquid helium vessel (diameter $27 \mathrm{~cm}$, height $60 \mathrm{~cm}$ ), a radiation heat shield and an outer vacuum vessel. The set-up is fabricated of either aluminium or copper to avoid activation problems. The bath can be filled at $4.2 \mathrm{~K}$ and cooled to $1.8 \mathrm{~K}$ by pumping. A PID controlled valve regulates the bath pressure. Unirradiated sensors measure the bath pressure. The temperature is obtained both by a helium bulb and resistive thermometers. The irradiation cryostat, in its actual configuration, cannot operate in pressurised helium. The sensors are limited to measure only the bath saturation pressure. At $1.8 \mathrm{~K}$, the pressure is then 60 times below LHC operating conditions.

\section{EXPERIMENTAL PROCEDURE AND RESULTS}

\section{Irradiation at low Temperature}

The effects during irradiation in saturated helium at $4.2 \mathrm{~K}$ (1 bar) and $1.8 \mathrm{~K}$ (16.4 mbar) are investigated. A preliminary in-situ calibration allows deduction of the correspondence between signal and measured pressure. The presented data concern only the latest irradiation, performed in June 1999. The first beam lasted eight hours for a total neutron dose of $3.4 \times 10^{14}$ $\mathrm{n} / \mathrm{cm}^{2}(\mathrm{~T}=4.2 \mathrm{~K})$; the second beam, performed at $1.8 \mathrm{~K}$, induced a neutron dose of $1.6 \times 10^{14}$ $\mathrm{n} / \mathrm{cm}^{2}$ in three hours of irradiation; and the last beam was performed at $4.2 \mathrm{~K}$ for $2.5 \times 10^{14}$ $\mathrm{n} / \mathrm{cm}^{2}$ in five hours (Table 2).

Sensor 1. No visible effect could be observed during the irradiation of this sensor.

Sensor 2. We observe two phenomena (Figure 3): when the beam starts, the measured pressure increases by about 7 mbar with an exponential saturation curve $\left(y=y 0+A \cdot\left(1-e^{-t / \tau}\right)\right)$; then drops continuously; this descent does not stop with the beam. It indicates a radiationinduced leak on the reference vacuum, the inner pressure of which tends to reach the outer pressure, resulting in a lower pressure difference and a decrease of the signal. This leak makes the analysis of the following runs difficult as the pressure varies from 1 bar to 16 mbar.

Table 2. The experiment performed in June 1999

\begin{tabular}{|c|c|c|c|c|}
\hline Event & Temperature & Pressure & Duration & $\begin{array}{l}\text { Accumulated } \\
\text { neutron dose }\end{array}$ \\
\hline Warm calibration & $300 \mathrm{~K}$ & 1 bar $=>4$ mbar & - & 0 \\
\hline Cold calibration & $4.2 \mathrm{~K}=>1.8 \mathrm{~K}$ & 1 bar $=>16$ mbar & - & 0 \\
\hline Irradiation 1 & $4.2 \mathrm{~K}$ & 1 bar & 8 hours & $3.4 \times 10^{14} \mathrm{n} / \mathrm{cm}^{2}$ \\
\hline Irradiation 2 & $1.8 \mathrm{~K}$ & 17 mbar & 3 hours & $5 \times 10^{14} \mathrm{n} / \mathrm{cm}^{2}$ \\
\hline Irradiation 3 & $4.2 \mathrm{~K}$ & 1 bar & 5 hours & $7.5 \times 10^{14} \mathrm{n} / \mathrm{cm}^{2}$ \\
\hline Cold calibration & $4.2 \mathrm{~K} \Rightarrow>1.8 \mathrm{~K}$ & 1 bar $=>16$ mbar & - & \\
\hline Warm calibration & $300 \mathrm{~K}$ & $1 \mathrm{bar}=>4$ mbar & - & \\
\hline
\end{tabular}




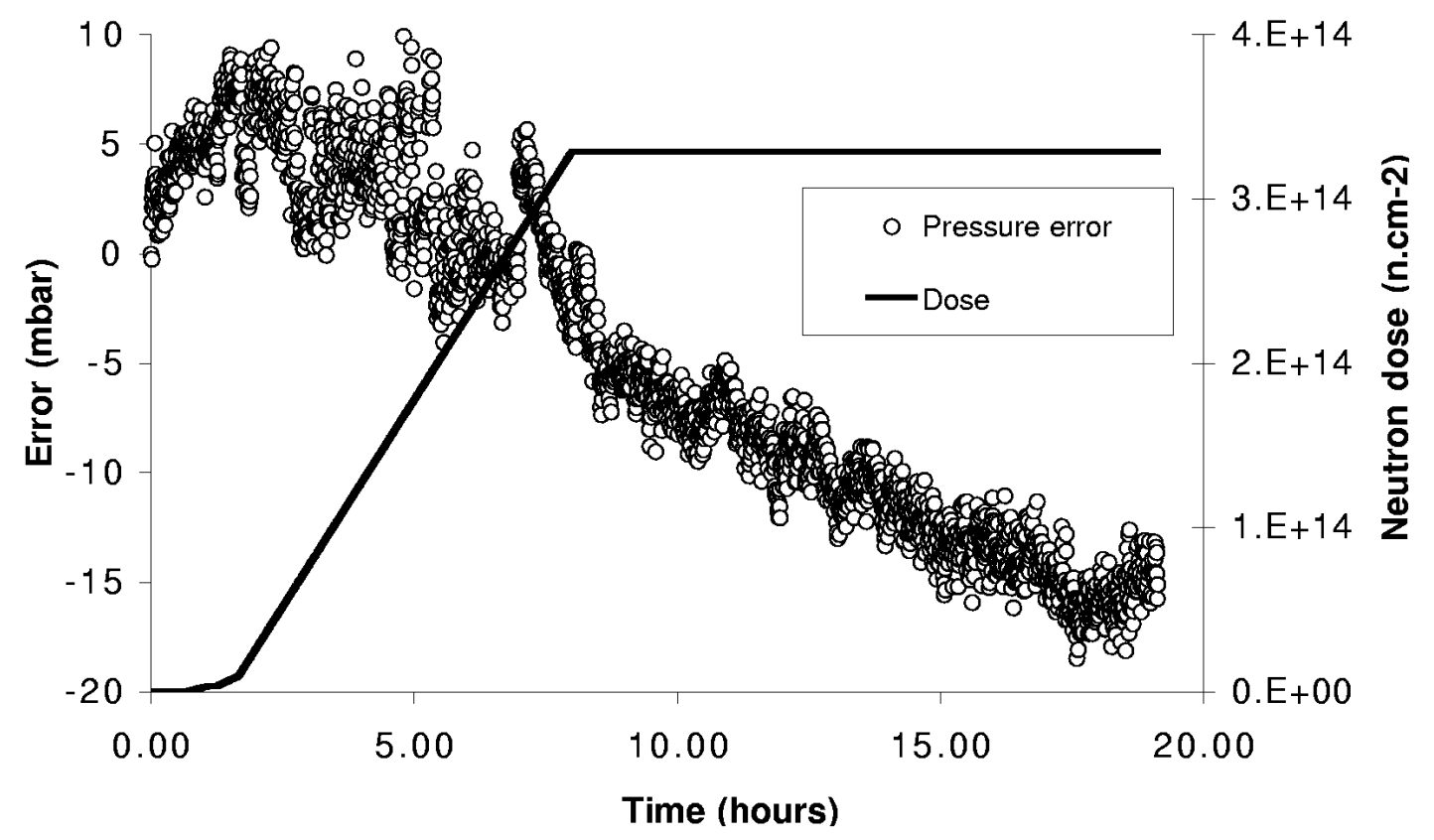

Figure 3. Influence of neutron irradiation on sensor 2 when irradiated at $4.2 \mathrm{~K}$. The long descent of the measured pressure indicates a leak in the sealed reference vacuum.

Sensor 3. The signal of this sensor drops when the beam is on (Figure 4). The descent follows an exponential saturation curve. A high influence of neutron irradiation on the internal diode-type thermometer of this transducer is observed: its read-out decreases proportionally to the neutron dose. No leak appears on this sensor. After this first drop at $4.2 \mathrm{~K}$, the sensor seems "saturated", and no further radiation effect occurs.

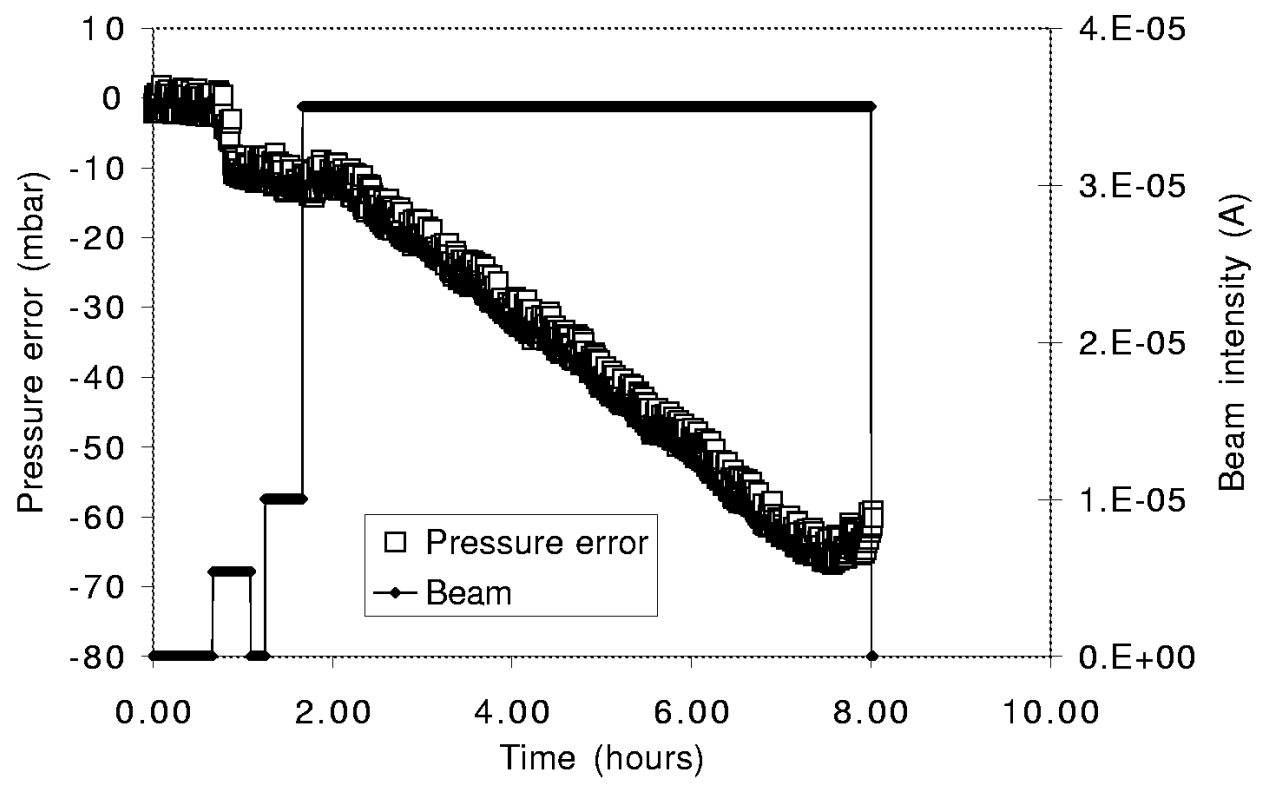

Figure 4. Neutron irradiation of sensor 3, first beam performed at $4.2 \mathrm{~K}$. The measured pressure drops when the beam is on

Paper presented at the CEC-ICMC'99 - July 12-16, 1999 - Montreal -Quebec, Canada 
Sensor 4. A high noise level is measured on this sensor $\left(\sigma_{\mathrm{P}}=10 \mathrm{mbar}\right.$ at atmospheric pressure), and its calibration was not possible in superfluid helium, because of the important nonlinearity of the transducer readout with the temperature. At $4.2 \mathrm{~K}$ a decrease $(-30 \mathrm{mbar})$ of the measured pressure with a saturation curve is observed. After the irradiation, the sensor recovers its initial reading in less than one hour. The same kind of behaviour is observed at 1.8 K. No leak was observed at low temperature.

\section{Variation of Calibration Curve at Low Temperature}

The transducers were calibrated in saturated liquid helium before and after the irradiation (between $1.8 \mathrm{~K}$ and $4.2 \mathrm{~K}$, corresponding to a bath pressure ranging from 19 mbar to 1 bar). As the transducer read-outs are temperature dependant, this experiment cannot be considered as a pressure calibration which would have to be performed in pressurised liquid helium. It is just a qualitative appreciation of the radiation stability of the transducer's characteristics. The total neutron dose received between these calibrations is $7.5 \times 10^{14} \mathrm{n} / \mathrm{cm}^{2}(15 \mathrm{kGy})$ in 16 hours of irradiation. The curves of Figure 5 show the results of these calibrations. The effects are low on sensors 2 and 3, which just show a small offset on the output signal. For sensor 1, the signal at 1 bar is almost unchanged, but the curve is modified for lower pressures.

\section{Behaviour of the Transducers after Final Warm-up}

After irradiation, a warm calibration is performed $(\mathrm{T}=300 \mathrm{~K})$. Three of the measured sensors are leaking, which makes them unusable (Figure 6). The shift of the sensors, the sensitivity (estimated with a quick 1-0-1 bar pressure cycle) and the time constant of the leaks are measured. All results are summarised in table 3 .
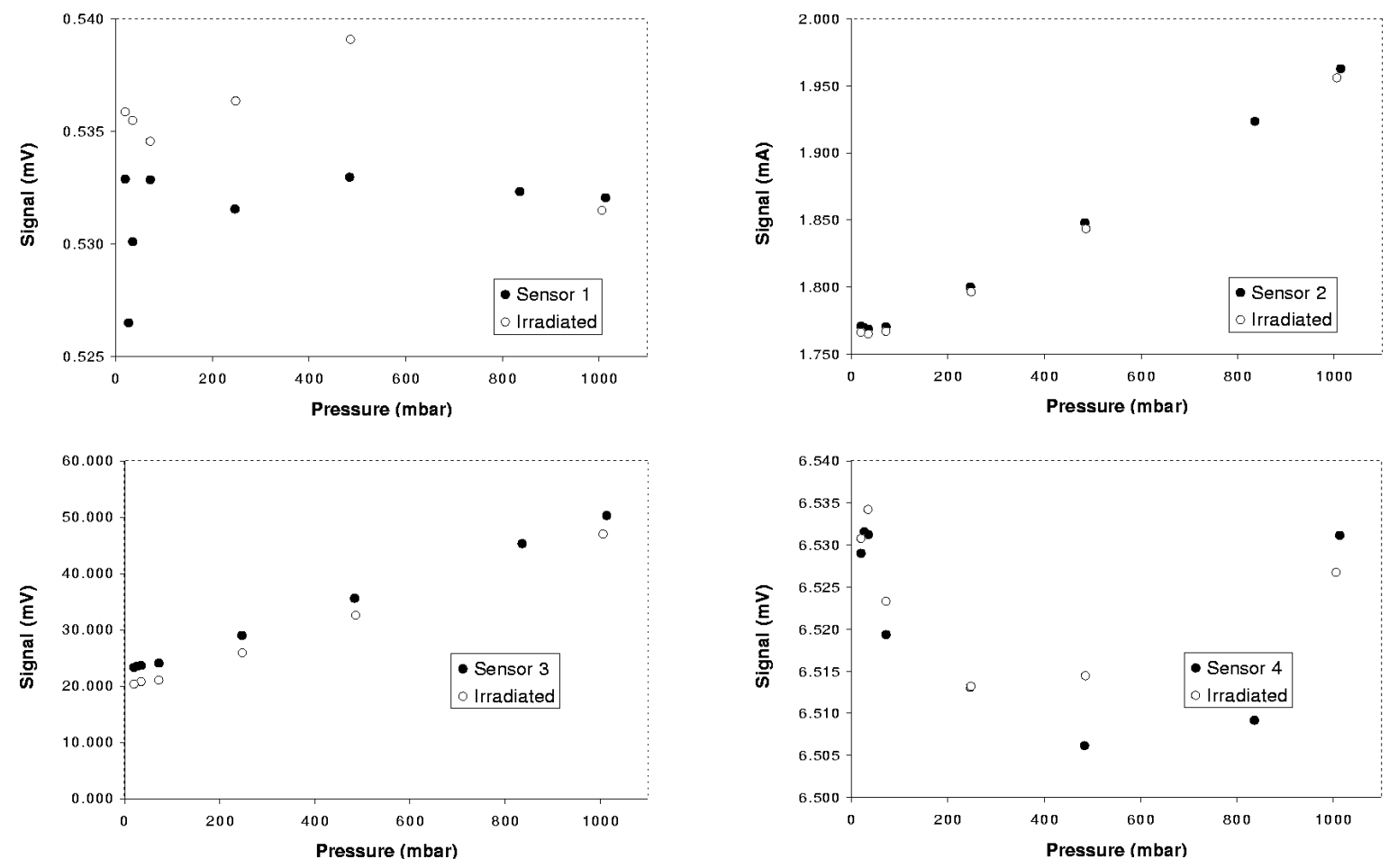

Figure 5. Comparison of cold calibrations performed before and after irradiation 


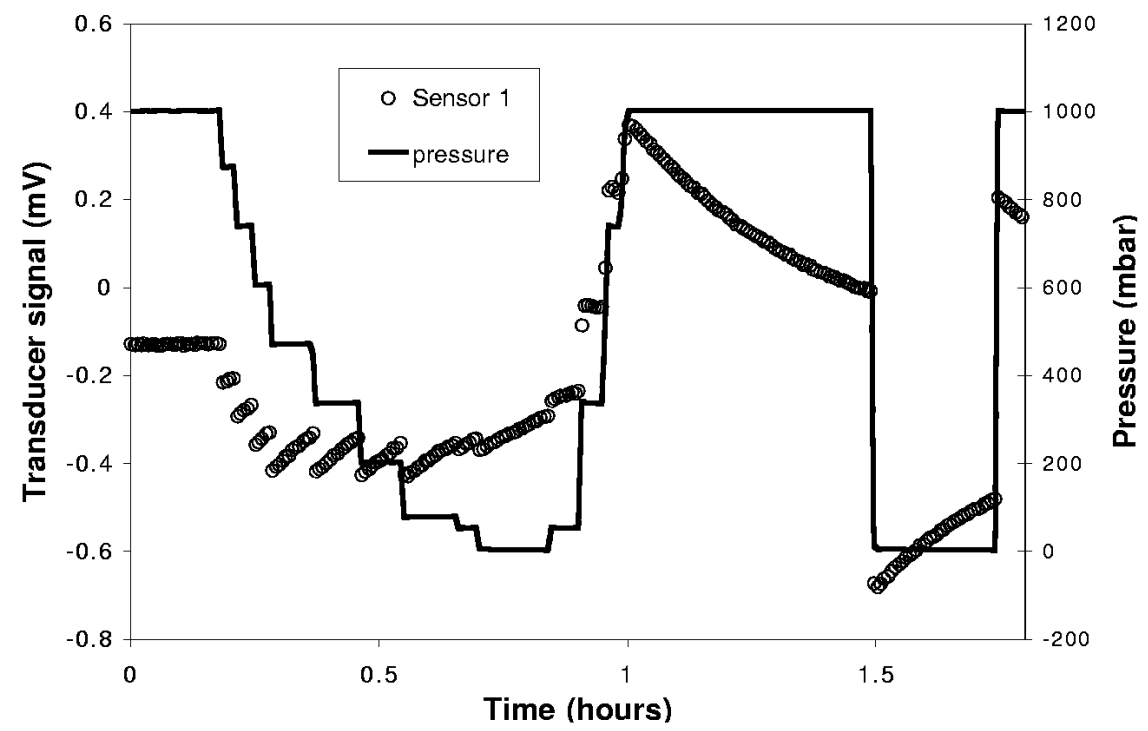

Figure 6. Evidence of a leak at room temperature after cold irradiation of sensor 1 . The signal changes with the pressure, and then reaches (with a time constant of 15 minutes) the "vacuum" signal $(-0.14 \mathrm{mV})$.

Table 3. Summary of the experimental campaign

$\begin{array}{lll}\text { Sensor } 1 & \text { Sensor } 2 & \text { Sensor } 3\end{array}$

Sensor 4

On-line observed drift at

$4.2 \mathrm{~K}\left(3.4 \times 10^{14} \mathrm{n} / \mathrm{cm}^{2}\right)$

0

*

-60 mbar

-30 mbar

Observed radiationinduced leak in liquid

No

Yes

No

No

helium

Radiation-induced

pressure error at 1 bar,

$4.2 \mathrm{~K}\left(7.5 \times 10^{14} \mathrm{n} / \mathrm{cm}^{2}\right)$

Radiation-induced pressure shift at 1 bar, $300 \mathrm{~K}$ (warm calibration)

\section{Measured signal change for $\Delta \mathrm{P}=1$ bar before irradiation \\ Measured signal change for $\Delta \mathrm{P}=1$ bar after irradiation temperature after irradiation \\ Observed leak at room}

$$
0.63 \mathrm{mV}
$$

$0.21 \mathrm{~mA}$

$10.6 \mathrm{mV}$

$1.25 \mathrm{mV}$

Time constant of the warm leak

Yes

2 hours

$$
\text { No }
$$

Yes 


\section{CONCLUSION}

The irradiation campaign was difficult to conduct. To limit radiation hazards the manufacturers were requested to provide pressure sensors with a minimum possible amount of stainless steel as this material has a strong activation when exposed to neutrons. The observed leaks are probably due to a lack of expertise of the manufacturers to work with lighter materials such as aluminium or copper-beryllium. From the experiments, one can draw conclusions concerning the elastic membrane and the deformation gauge; some of the sensors exhibited a drift varying with the received radiation dose. To investigate whether leaks were produced on the membrane by irradiation it will be necessary to proceed to electron microscopic analysis.

\section{ACKNOWLEDGEMENTS}

We would like to thank F. Châtelet, C. Joly (IPN Orsay) and P. Romand (CERN) for their participation to the experiments. We also want to thank C. Balle, G. Bertrand, J.C. Grivat, R. Orfila, P. Portier and N. Vauthier (CERN); J. Collot, Ph. Martin and G. Mondin (ISN Grenoble, CNRS-IN2P3, France); and J.C. Bajard, G. Blondiaux and the cyclotron group (CERI, CNRS Orléans, France) for their help. Finally, we thank L. Thomé (CSNSM Orsay, CNRS-IN2P3, France) for fruitful discussions, W. Erdt and Ph. Lebrun for their support.

\section{REFERENCES}

1. K.M. Potter, H. Schonbacher, G.R. Stevenson, "Estimates of Dose to Components in the Arcs of the LHC due to Beam-Loss and Beam-Gas Interactions", CERN-LHC report \#18 (1995)

2.T. Bager, J. Casas-Cubillos and L. Metral, "Cryogenic pressure calibration facility using a cold force reference", paper submitted to CEC-ICMC 1999 (Montréal) 